\title{
Percepções e ações dos enfermeiros em relação ao racismo institucional na saúde pública
}

Nurses perceptions and actions about institutional racism in public health

Percepciones y acciones de los enfermeros con relación al racismo institucional en la salud pública

\section{Luiz Gustavo Fernandes da Rosa', Renata Gomes Christóvão" ${ }^{\mathrm{II}}$, Mirela Furlin ${ }^{\mathrm{III}}$ Jeanice Baecker Lasta ${ }^{\mathrm{IV}}$}

Resumo: Objetivo: conhecer as percepções e as ações dos enfermeiros em relação ao racismo institucional na saúde pública. Método: pesquisa qualitativa, descritiva e exploratória, com amostra constituída por nove enfermeiros da Rede de Atenção à Saúde de um município do litoral norte do Rio Grande do Sul, sendo os dados coletados por entrevistas semiestruturadas, analisadas conforme o Método de Análise de Conteúdo. Resultados: revelaram-se três categorias: Conhecimentos sobre saúde da população negra, ações e prevenção frente ao racismo institucional; Vivência de situações de racismo, existência de discriminação e desigualdade no acesso aos serviços de saúde; Conhecimento e opinião sobre a Política Nacional de Saúde Integral da População Negra e Racismo Institucional. Considerações finais: os enfermeiros percebem o racismo institucional de forma distorcida, com reduzido conhecimento e provimento de ações voltadas à saúde da população negra. Porém, ressaltam meios educativos para a prevenção e desconstrução do racismo institucional na saúde pública.

Descritores: Racismo; Enfermagem; Saúde pública.

Abstract: Aim: to know the perceptions and actions of nurses in relation to institutional racism in public health. Method: qualitative, descriptive and exploratory research, with a sample of nine nurses from a city on the north coast of Rio Grande do Sul. Data were collected through semi-structured interviews, analyzed according to the Content Analysis Method. Results: three categories emerged: knowledge about the health of the black population, actions and prevention against institutional racism; Experience in situations of racism, existence of discrimination and inequality in access to health services; Knowledge and opinion on the National Policy of Comprehensive Health of the Black Population and Institutional Racism. Final considerations: nurses perceive institutional racism in a distorted way, with reduced

\footnotetext{
${ }^{\text {I }}$ Enfermeiro. Residência Multiprofissional em Saúde Comunidade. Universidade Luterana do Brasil (ULBRA). Canoas, RS, Brasil. E-mail: enfermeiro.luizgustavofr@outlook.com. ORCID: https://orcid.org/0000-0001-7509-0635

${ }^{\text {II }}$ Enfermeira. Especialização em Materno-infantil. Faculdade de Ciências da Saúde Moinhos de Vento. Porto Alegre (RS), Brasil. E-mail: renatachristovao@outlook.com. ORCID: https://orcid.org/0000-0002-9480-0548

${ }^{\text {III }}$ Enfermeira. Universidade Luterana do Brasil (ULBRA). Torres, RS, Brasil. E-mail: miramscs@yahoo.com.br. ORCID: https://orcid.org/00000002-9194-6533

IV Enfermeira. Mestre em Educação. Universidade Luterana do Brasil (ULBRA). Torres, RS, Brasil. E-mail: jelasta@hotmail.com. ORCID: https://orcid.org/0000-0002-9802-7687
} 
Percepções e ações dos enfermeiros em relação ao racismo institucional na saúde pública $\mid 2$

knowledge and provision of actions directed to the health of the black population. However, they emphasize educational means for the prevention and deconstruction of institutional racism in public health.

Descriptors: Racism; Nursing; Public health.

Resumen: Objetivo: conocer las percepciones y las acciones de los enfermeros con relación al racismo institucional, en la salud pública. Método: investigación cualitativa, descriptiva y exploratoria, con muestra constituida por nueve enfermeros de un municipio del litoral norte de Rio Grande do Sul; los datos fueron recolectados por medio de entrevistas semiestructuradas, analizadas a partir del Método de Análisis de Contenido. Resultados: se revelaron tres categorías: conocimientos sobre salud de la población negra, acciones y prevención frente al racismo institucional; vivencia de situaciones de racismo, existencia de discriminación y desigualdad en el acceso a los servicios de salud; conocimiento y opinión sobre la Política Nacional de Salud Integral de la Población Negra y Racismo Institucional. Consideraciones finales: los enfermeros comprenden el racismo institucional de forma distorsionada, con reducido conocimiento y provisión de acciones direccionadas a la población negra. Sin embargo, resaltan medios educativos para la prevención y desconstrucción del racismo institucional en la salud pública.

Descriptores: Racismo; Enfermería; Salud pública.

\section{Introdução}

No cotidiano do trabalho, o racismo institucional pode ser encontrado em meio às práticas dos profissionais e das organizações prestadoras de serviço, apresentando-se em atitudes excludentes, ignorantes e preconceituosas fundamentadas por normas e práticas preestabelecidas e aceitas, formando barreiras ao acesso da população negra às vantagens e benefícios que lhe são de direito pelas instituições. ${ }^{1}$ No âmbito da saúde pública, as evidências da desigualdade colocam em pauta o paradoxo do Sistema Único de Saúde (SUS), no qual 70\% dos usuários são pessoas negras e, tais evidências, podem ser constatadas por meio de dados epidemiológicos que apontam elevadas taxas de mortalidade materno-neonatal e violências sofridas por esta população, abalando diretamente a qualidade e a expectativa de vida dos mesmos. $^{2}$

Visando a promoção e a garantia da equidade em saúde para a população negra, instituiuse a Política Nacional de Saúde Integral da População Negra (PNSIPN) por meio da portaria $\mathrm{n}^{\circ}$ 992 de 13 de maio de 2009, desdobrando-se sobre as desigualdades com as quais este segmento populacional se encontra ligado frequentemente, assegurando a promoção da igualdade racial e a efetivação da equidade e do acesso ao direito à saúde, enfocando todos os aspectos que 
envolvem a mesma. ${ }^{3}$ Embora isso, os profissionais da equipe de atenção primária à saúde, em seu contexto e compreensão, reforçam a inexistência do racismo, bloqueando as ações do sistema frente a tais situações. ${ }^{4}$

Quando uma instituição, em seu exercício, não se encontra em condições de prestar o serviço de forma correta e adequada, baseando-se nas necessidades e nos interesses de determinada população devido a influência de pré-conceitos e dificuldades frente a aspectos étnicos, raciais e de cor de pele, pode-se dizer que o racismo institucional está sendo exercido. ${ }^{5}$

Os enfermeiros são parte integrante relevante da saúde pública. Levando-se em consideração todos os aspectos que envolvem a mesma e a efetividade dos princípios do SUS para com a população negra, considera-se importante a compreensão da percepção destes profissionais quanto ao racismo institucional e suas ações frente a tais situações já que, frequentemente, encontram-se envolvidos com a organização dos serviços e possuem maior vínculo com os usuários. A partir disso, pode ser possível oferecer fundamentos que promovam conhecimentos e modificações em suas ações e rotinas ou reforcem aquelas consideradas adequadas, com o intuito de proporcionar cuidado integral e equânime à população negra de forma justa e eficaz. Diante desta realidade, a pesquisa desenvolveu-se com base na seguinte questão: Qual a percepção e as ações dos enfermeiros quanto ao racismo institucional na saúde pública? Para compreender este problema, o estudo teve como objetivo: conhecer as percepções e ações dos enfermeiros em relação ao racismo institucional na saúde pública.

\section{Método}

Trata-se de uma pesquisa qualitativa, com abordagem descritiva e exploratória, que foi realizada no município de Capão da Canoa, no litoral norte do Estado do Rio Grande do Sul, no período de julho a novembro de 2016. Participaram do estudo nove enfermeiros em atividade assistencial na Rede de Atenção à Saúde do município, selecionados a partir do número de unidades de saúde em funcionamento, perfazendo um total de nove, um profissional para cada 
Percepções e ações dos enfermeiros em relação ao racismo institucional na saúde pública... 4

unidade, entendendo que estes são responsáveis pela gestão dos serviços e assistência de enfermagem na realidade estudada. Nas unidades que possuíam mais de um enfermeiro - duas unidades com quatro enfermeiros em seu quadro de pessoal -, sorteou-se o participante. Foram estabelecidos como critérios de inclusão, enfermeiros que estivessem atuando nas unidades municipais de saúde, trabalhando no dia estipulado para a pesquisa. Como critério de exclusão, foram adotados enfermeiros que estivessem atuando em outros setores do serviço público de saúde do município.

Foram realizadas visitas nas unidades de saúde durante o mês de agosto de 2016, quando os enfermeiros em exercício profissional foram convidados a participar da pesquisa, por meio de uma entrevista semiestruturada - foi elaborado um roteiro de perguntas com base nas variáveis de estudo: a percepção dos enfermeiros em relação ao racismo institucional na saúde pública e as ações destes frente a tais situações no dia a dia de trabalho. Tal instrumento foi constituído por sete questões abertas, formuladas de acordo com o conceito de "racismo institucional" e com embasamento teórico na Política Nacional de Saúde Integral da População Negra adotados pelo Ministério da Saúde. Após as gravações das entrevistas em mp3, estas foram transcritas a fim de facilitar a análise do material, procedida de acordo com o método de Análise de Conteúdo. ${ }^{6}$

Inicialmente, foi realizada a leitura flutuante do material levantado, de maneira a possibilitar o conhecimento de todas as informações obtidas e, pela regra de homogeneidade na constituição do corpus, foi possível o alcance dos dados brutos, permitindo a definição das unidades de registro e de contexto, além da codificação dos dados na análise temática. As informações foram apresentadas de acordo com o anonimato, preservando a integridade dos participantes da pesquisa. Utilizaram-se códigos de identificação nos quais a letra “E” refere-se à categoria profissional participante, os enfermeiros, e é seguida de um ponto e um número em ordem crescente como, por exemplo, em E.3. 
A partir deste primeiro tratamento do material, a categorização dos elementos levantados se tornou possível com base no seu agrupamento em categorias, conforme as suas semelhanças em dado aspecto da sua constituição e/ou semântica, segundo os princípios de qualidade como a exclusão mútua, a homogeneidade, a pertinência, a objetividade e a fidelidade e a produtividade. Em seguida, realizou-se a análise das informações que viabilizou o alcance de inferências e interpretações por meio do estudo das variáveis inferidas e de inferências no contexto revelado pelo material coletado para a pesquisa. A discussão sobre os dados coletados foi realizada em conjunto com bibliografias científicas atualizadas pertinentes sobre o tema em questão.

Para a realização da pesquisa obteve-se aprovação do Comitê de Ética em Pesquisa Envolvendo Seres Humanos da Universidade Luterana do Brasil, Canoas, sob o parecer: 1.521.570, número CAAE: 55120516.1.0000.5349 em 29 de abril do ano de 2016, atendendo às exigências da Resolução 466/2012 do Conselho Nacional de Saúde.

\section{Resultados e discussão}

Entre os participantes deste estudo, seis eram do sexo feminino e três do masculino, com idades entre 33 e 62 anos; seis trabalhavam em Estratégia de Saúde da Família (ESF), dois em Pronto Atendimento e um no Centro de Atenção Psicossocial; todos com oito ou mais anos de formação, sendo que apenas dois atuavam na rede há mais de cinco anos.

Após a Análise de Conteúdo, estabeleceram-se três categorias, sendo elas: Conhecimento e opinião sobre a Política Nacional de Saúde Integral da População Negra e Racismo Institucional; Vivência de situações de racismo, existência de discriminação e desigualdade no acesso aos serviços de saúde; Conhecimentos sobre saúde da população negra, ações e prevenção frente ao racismo institucional. 
Percepções e ações dos enfermeiros em relação ao racismo institucional na saúde pública... 6

Conhecimento e opinião sobre a Política Nacional de Saúde Integral da População Negra e Racismo Institucional

A Política Nacional de Saúde Integral da População Negra mostrou-se desconhecida por grande parte dos profissionais enfermeiros durante a realização da entrevista.

Eu não conheço essa política, nunca fui a fundo! Então não tenho conhecimento. (E.3)

Sei que tem, mas realmente nunca tive maior contato sobre isso. (E.5)

Para alguns pesquisadores, os gestores dos serviços de saúde necessitam saber da existência da PNSIPN, reconhecendo-a como uma ferramenta para o combate à discriminação nos serviços do SUS e produto de lutas históricas desta população pelo alcance de seus direitos, assegurando a efetivação destes por meio do respeito à cidadania da população negra e suas necessidades. ${ }^{7}$

A PNSIPN possui caráter transversal e visa o combate à discriminação étnica e racial ao nível dos serviços públicos de saúde oferecidos pelo SUS, ampliando o acesso deste segmento da população a serviços de saúde de qualidade, sanando as suas necessidades e garantindo a integralidade dos cuidados. ${ }^{3} \mathrm{O}$ seu reconhecimento enquanto ferramenta para a prevenção do racismo deve entender que a desconstrução deste exige o desenvolvimento de estratégias intersetoriais que envolvam, principalmente, a saúde e a educação para o fortalecimento do controle social e transformação das relações sociais discriminatórias de forma mais abrangente e que perpasse o setor saúde. ${ }^{8}$

Entretanto, a falta de atenção para os aspectos mais abrangentes da saúde da população pôde ser observada nas entrevistas, nas quais a maioria dos participantes não opinou sobre a política ou consideraram-na desnecessária.

Eu vou ser bem franco, eu acho que não seria, na minha opinião, pelo menos pra nossa região, [...] é uma política desnecessária, eu acho que nós, na nossa região, a gente não enfrenta essa diferença, racial, não é tão presente, tão forte. Eu não vejo um real favorecimento dessa população através dessa política. Talvez seja porque até, eu não conheça essa política. (E.5) 
A PNSIPN muitas vezes é considerada como desnecessária por profissionais da atenção básica por ser vista como uma afronta ao princípio de igualdade de acesso aos serviços do SUS, já que acreditam que a população negra não sofre discriminações sociais nos dias atuais. Este é o resultado da crença da inexistência de discriminação entre as raças no Brasil, aliado a pouca informação em relação à política e o seu teor de equidade. ${ }^{9}$ Além disso, os enfermeiros desconheciam, em sua unanimidade, o significado do termo "racismo institucional" e, aqueles que supuseram um significado para o termo, concentraram-se apenas em situações de racismo dentro da equipe de enfermagem ou dentro da equipe da instituição de saúde, esquecendo da influência deste problema sobre os usuários do serviço. Deste modo, os profissionais demonstram entender o termo "racismo institucional" como os processos de discriminação raciais que ocorrem restritamente no funcionamento e organização da “instituição de saúde”.

Eu não conheço também, não sei. Racismo a gente sabe que é racismo, mas o que significa? Daí eu não sei. (E.3)

Olha, racismo institucional é tu ter funcionários de cor negra e tu não favorecer ela sobre a possibilidade de ela ter promoções, eu penso que seja dessa forma assim, entendeu? (E.5)

Pesquisadores indicam que o racismo institucional constitui em práticas e ações racistas e discriminatórias que possuem caráter silencioso de atuação, consequentemente, sendo difícil o seu reconhecimento. Entretanto, com uma atenção direcionada e crítica para a realidade, é possível perceber tais situações no dia a dia do serviço público de saúde. ${ }^{10}$ Ademais, de acordo com um estudo acerca do assunto, os enfermeiros da atenção básica possuem percepções pouco fundamentadas da saúde da população negra, ressaltando a importância da implementação da PNSIPN e a consideração por parte destes profissionais, já que, mesmo sendo majoritariamente significante na saúde pública, a população negra, de uma forma geral, ainda se encontra em baixas condições de saúde. ${ }^{5}$

O racismo institucional compreende a segregação provocada quando uma instituição atua por meio de comportamentos excludentes e discriminatórios, com práticas baseadas em 
Percepções e ações dos enfermeiros em relação ao racismo institucional na saúde pública... $\mid 8$

pré-conceitos e ignorância frente aos aspectos étnicos e raciais em seus processos de trabalho. Desta maneira, consequentemente, deixa de prestar a assistência adequada, submetendo tais populações a situações de desprovimento do serviço e desvantagens. ${ }^{3}$

$\mathrm{Na}$ esfera da saúde, o racismo institucional pode ser encontrado em diversos pontos de sua constituição, desde a recusa em reconhecer as especificidades da população negra e as diferenças de adoecimento entre as raças, até a falta de conhecimento, debate e especialização dos profissionais de saúde no que tange às questões raciais, além de ações racistas ligadas às atuações profissionais como atitudes excludentes e de diminuição do outro, abrangidos por olhares, silêncio e desinteresse pela assistência. ${ }^{11}$

Vivência de situações de racismo, existência de discriminação e desigualdade no acesso aos serviços de saúde

Em relação às vivências de situações de racismo, todos os enfermeiros citaram que nunca vivenciaram, nem presenciaram, durante a sua carreira profissional, nos locais onde tenham trabalhado.

Nunca vi assim dizer: Não, não vou atender! Ah! Atende aquele porque é negro, não! Da nossa parte dos brancos com os negros. Agora os negros se fazem inferior, eu não sei o porquê, eu digo: até na faculdade aí, bolsa para negro! Para quê bolsa para negro? [...] Vamos à luta, vamos estudar que tu chega lá. Essas bolsas para negro não precisava ter, por que isso sim está fazendo racismo. (E.1) Ah! eu nunca presenciei, [...] nunca passei por uma situação assim. Pensando bem, agora, nunca!(E.2)

Em contrapartida, um estudo demonstrou que 48,6\% dos pretos e $40,5 \%$ dos pardos declararam perceber algum tipo de situação racista nos serviços públicos de saúde. A dificuldade em perceber situações de racismo e compreender a realidade de saúde da população negra no Brasil, pode ser explicada pelo fato de o país possuir uma construção social surreal de paz entre as etnias, baseada na teoria da mestiçagem, também conhecida como "mito da democracia racial". Tal teoria 
afirma que todas as pessoas têm possibilidades iguais de acesso a bens e serviços sociais e, assim, galgam, individualmente, o sucesso de forma igualitária. ${ }^{9}$

O racismo, no Brasil, tomou caminhos ao longo da história que o permitiram permanecer internalizado na sociedade, pois o respeito imposto com as conquistas da população negra pela dignidade e a construção de um falso ideário de democracia racial, determinaram o escamoteamento da discriminação racial em uma lógica de repressão social ineficiente. Desta maneira, o racismo institucional baseia-se na prática e não na manifestação propriamente dita, ou seja, as ações racistas ocorrem de maneira pouco evidente e perceptível, através de atos rotineiros, internalizados nos costumes e culturas, inferiorizando os negros nas diversas faces da sua vida social. ${ }^{12}$ A concepção de democracia racial pode ser observada nas falas dos enfermeiros ao demonstrarem acreditar na inexistência de discriminação e desigualdade no acesso à saúde pela população negra.

Não vejo! [...], não tem discriminação. (E.1)

Não, acho que agora não mais, acho que já teve bastante em qualquer instituição, mas acho que agora não mais, acho que agora até é igual o atendimento. (E.6)

No Brasil, as relações entre classes e raças possuem discrepâncias em suas manifestações e no funcionamento social, as quais refletem diretamente na saúde, podendo esta ser definida como produto de diversos fatores políticos, econômicos, ambientais, sociais e culturais os quais, muitas vezes, de forma tangencial, mantêm o racismo de maneira dinâmica no coletivo populacional, fomentando as desigualdades. ${ }^{13}$ Deste modo, a população negra, permanece, atualmente em situação de vulnerabilidade social. Isso se dá devido ao pouco reconhecimento da existência da discriminação racial ainda nos dias atuais, influenciado pelo racismo institucional, contribuindo para a formação e manutenção de uma sociedade estruturada sobre a desigualdade. ${ }^{14}$

O provimento de espaços de formação profissional e promoção da educação permanente tem potencial para o desenvolvimento do empoderamento necessário à desconstrução da 
Percepções e ações dos enfermeiros em relação ao racismo institucional na saúde pública... $\mid 10$

discriminação. Tal discriminação faz-se de forma presente, tanto nas relações sociais como na produção científica já que, não infrequentemente, o racismo institucional encontra-se presente nas organizações em um processo de manutenção da desigualdade e exclusão social, capaz de atingir diretamente a qualidade da assistência à saúde oferecida à população negra. ${ }^{15}$

Conhecimentos sobre saúde da população negra, ações e prevenção frente ao racismo institucional

Os enfermeiros entrevistados, em sua maioria, ressaltaram a necessidade de um maior escopo de conhecimentos sobre saúde da população negra para o oferecimento de ações e serviços de saúde de qualidade para este segmento. Quando foi realizada a pergunta "Dentro do seu escopo de conhecimentos, você acha que sabe o bastante sobre a saúde da população negra para ofertar ações de qualidade na sua assistência? Justifique!”, obtiveram-se respostas que refletem o despreparo profissional para a prática diária de qualidade na comunidade ante a população negra. Um dos profissionais até mesmo reconheceu que este é um tema que deve ser mais debatido e evidenciado na profissão.

Eu precisava de alguma especialização, algum apoio melhor. (E.1)

Não, acho que não, tem que aprender muito mais. (E.2)

Não, acho que isso ainda é uma coisa que precisa ser bem discutida porque têm muitas coisas que são diferentes, então eu acho que é uma coisa que precisa ser mais evidenciada. (E.6)

A educação em enfermagem firmou-se historicamente sobre os alicerces da atenção biomédica desde que iniciou como ciência da saúde voltando-se, em muitos casos, apenas para os aspectos técnicos da profissão e esquecendo-se de fatores sociais de saúde na abordagem do ensino, assim como a cultura e a questão econômica, que influenciam diretamente nas condições de saúde da população negra. Em um estudo que aborda a problemática, foi possível observar que os enfermeiros não possuíam conhecimentos fundamentados sobre a relação raça e saúde e as suas influências no processo saúde/doença desta população, aspectos estes que dificultam uma visão mais abrangente dos profissionais sobre os determinantes sociais de saúde 
deste segmento populacional, muitas vezes, esbarrando em ações ineficazes ou até afastando os usuários, devido ao fato de não terem as suas necessidades atendidas. ${ }^{16}$

O enfermeiro, enquanto pessoa e ator social, influencia a sociedade e é influenciado por esta podendo, deste modo, prevenir ou reproduzir o racismo nas suas ações. A partir desta concepção, entende-se que para a desconstrução do racismo institucional, o profissional deve apoiar-se em conhecimentos sólidos sobre o assunto para que possa trabalhar as verdadeiras necessidades da população negra. ${ }^{17} \mathrm{~A}$ compreensão das dinâmicas de discriminação e desigualdade é a base para entender o processo saúde-doença de um grupo. Para isso, é necessária a análise mais aprofundada da sua situação de vida e saúde, capaz de alcançar a constituição de um corpus de conhecimento que abranja a verdadeira realidade de saúde de um segmento. Tal prática é essencial e ainda pouco presente nos processos de formação. ${ }^{18}$

Esta categoria profissional necessita ampliar os seus fundamentos com relação à população negra, devido a sua maior representatividade e vulnerabilidade em relação a certas doenças, como diabetes, hipertensão, anemia falciforme, miomas, deficiência de glicose 6fosfato desidrogenase e transtornos mentais. Tais fatores, quando ligados à susceptibilidade dos mesmos às baixas condições socioeconômicas estabelecidas pela sociedade e cultura, colaboram para o seu distanciamento dos serviços. ${ }^{17}$

No entanto, faz-se relevante salientar a existência de uma importante lacuna científica sobre o tema, marcada pelo reduzido aprofundamento na formação dos profissionais de saúde, capaz de comprometer diretamente a assistência às demandas deste público. ${ }^{19}$ Este fato pode ser explicado pelo reduzido apoio técnico para a realização de pesquisas, contribuindo para que os enfermeiros se distanciem do contingente populacional negro, desconhecendo as suas peculiaridades. As ações deste profissional são primordiais, já que por meio de sua visão e cuidado holísticos, pode compreender as situações e atuar de forma eficiente para com os negros, melhorando a qualidade de vida destes que vivem em um país considerado o segundo no mundo com o maior número de afrodescendentes, cercado de desigualdades e discriminações. ${ }^{5}$ 
Nas entrevistas, foi possível identificar que um evento de racismo no serviço de saúde é considerado, entre os enfermeiros, um sinal de alerta para o início de intervenções em educação e conscientização da equipe sobre a saúde da população negra e racismo institucional, com o objetivo de amenizar a situação para permitir o desenvolvimento do trabalho.

É, se fosse uma situação constrangedora, [...]. Tentaria amenizar? Conversar. [...] Muitas vezes a pessoa se magoa, por exemplo, se fosse um paciente? Magoa-se e [...], tentar articular formas de amenizar a situação, para poder dar andamento no atendimento, no que for ofertado àquela pessoa. (E.4)

Em um estudo realizado em unidades de ESF, as discussões acerca das políticas voltadas para a população negra foram definidas como estratégias facilitadoras para a implantação das mesmas e para a maior qualificação do cuidado prestado a este segmento. Compreende, além disso, estratégia eficaz no enfrentamento do racismo institucional, pois qualquer pessoa pode praticar o mesmo, sendo importante fonte para a afirmação da PNSIPN. ${ }^{20}$

De acordo com a literatura, os profissionais e gestores da saúde despreparados para atuar com a população negra podem constituir barreira para o acesso, reafirmando disparidades de saúde, marcadas por fatores socioeconômicos, classe social e raça. ${ }^{21}$ Neste contexto, considera-se importante a abordagem da saúde deste segmento ainda na formação dos profissionais, já que tal implementação permitiria uma melhora significativa nas condições de vida e saúde dessa parte da população por meio da ação em todos os níveis de atenção, respeitando as necessidades específicas, além de permitir a educação para a população, realização de pesquisas sobre o tema e viabilizar a gestão participativa dos serviços. ${ }^{7} \mathrm{O}$ trabalho sobre questões étnicas, raciais e discriminatórias na formação dos profissionais da saúde tem poder na desconstrução das desigualdades e no respeito às diferenças, além da formação de uma identidade equânime essencial para o trabalho em saúde, livre de qualquer ato discriminatório. ${ }^{22}$ Nesta premissa, os profissionais participantes percebem a orientação, capacitação e educação permanente e continuada para os profissionais, como forma de prevenir o racismo na saúde pública. 
Eu acho que, com certeza, é capacitar os profissionais, ofertar cursos, ofertar a política, mostrar a política, [...] para que a gente fique bem capacitado para atender as pessoas com igualdade. Eu acho que seria por aí, capacitar os profissionais, para que não aconteça esse tipo de situação. Eu acho que é por aí. (E.4)

A falta de discussão e troca de conhecimentos na equipe pode ser vista como fonte para a reprodução de atos discriminatórios e excludentes provenientes do racismo social brasileiro, viabilizando a reprodução do racismo institucional no serviço de saúde. O uso da informação e do debate sobre a saúde da população negra e as relações raciais nas quais está inserida é base para a prevenção do racismo institucional, já que permite que os profissionais desenvolvam uma atenção mais precisa às práticas que podem ser discriminatórias durante a sua atuação. ${ }^{11}$

Atualmente, o segmento populacional negro continua em estado de vulnerabilidade, propício a danos advindos do racismo social, além de estarem constantemente esquecidos em relação às ações das políticas públicas que lhe são de direito, inclusive, àquelas ligadas à saúde. ${ }^{23}$ Assim, é necessária a desconstrução do racismo no SUS por meio do manejo por parte dos gestores na promoção de formação e educação continuada dos profissionais, com vista a assegurar a prevenção e atenção aos agravos e necessidades particulares deste segmento populacional. ${ }^{24}$

O trabalho com a comunidade também foi ressaltado entre os entrevistados como uma maneira eficaz de prevenir o racismo em todas as suas formas, principalmente na saúde.

Eu acho que é a educação. A educação da população. E, principalmente, a educação para os próprios negros e para as próprias pessoas que passam por isso [...], educação permanente, alguma coisa assim, desse tipo. (E.3)

É, daí, na minha cabeça assim, eu penso que seria mais efetivo assim na fase infantil, crianças, bater na escola isso daí! Eu acho que agora, esse pessoal que tá vindo novo aí, como o ESF vem crescendo muito, eu acho que isso já deve tá sendo feito. (E.7)

O debate sobre o tema etnia e a apresentação da PNSIPN para a comunidade foi vista como necessária em um estudo realizado em Porto Alegre/RS, pois permite que a população 
compreenda os motivos pelos quais é necessária a coleta do quesito cor/raça em documentos do serviço de saúde e a importância do respeito às diferenças étnicas e culturais de cada segmento da população. ${ }^{20}$ Promover a igualdade racial não se restringe apenas ao fato de prover direitos à população negra mas, também, permitir que estes sejam alcançados e assegurar condições para a sua efetivação, diminuindo as barreiras para tal e garantindo a cidadania, com base no combate à discriminação racial socialmente desenvolvida. ${ }^{25}$

Compreendido isso na implementação de políticas públicas, faz-se necessária a atuação dos profissionais para com a comunidade, aproximando-se das suas características, considerando os sujeitos em todas as suas faces, respeitando a sua inserção sociocultural. ${ }^{4}$ Desta forma, no enfrentamento ao racismo, a atuação dos enfermeiros constitui parte importante na educação do paciente, família e comunidade, com meios informativos e campanhas que ajam no desenvolvimento do interesse público e social pela desconstrução do racismo, sendo educador permanente e viabilizando uma assistência livre de preconceitos e julgamentos, pautada da humanização, visando a atenção direcionada para cada caso, em especial, àqueles que envolvam violência. ${ }^{17}$

\section{Considerações finais}

Este estudo contribuiu para o levantamento de um tema complexo, carregado de formações históricas, culturais e interpessoais, que resultaram e ainda resultam em determinantes sociais responsáveis por significativos problemas de saúde à população negra. A pesquisa atingiu o seu objetivo de conhecer as percepções e ações dos enfermeiros em relação ao racismo institucional na saúde pública; os entrevistados desconheciam, em sua maioria, o termo "racismo institucional” e a PNSIPN, fato este que demonstrou o pouco domínio destes profissionais em relação às especificidades e necessidades deste segmento populacional, altamente significativo no setor público de saúde. 
Ainda nesta premissa, os entrevistados supuseram que o racismo institucional seja aquele que ocorre no interior das equipes de saúde. Tal percepção pode ser explicada pelo fato de o termo "institucional” estar relacionado às instituições. Entretanto, tal equívoco tem base na pouca frequência de debates entre os profissionais sobre as questões que envolvem raça, cor e etnia, além do reduzido acesso à formação, capacitação e educação permanente sobre saúde da população negra para a categoria, que ainda apresenta-se sustentada pelo olhar biomédico. Tal falta de capacitação e preparação é percebida pelos enfermeiros, sendo afirmada a sua necessidade para a oferta de um serviço de qualidade na saúde pública.

A dificuldade em perceber situações de discriminação no aceso à saúde e de racismo no cotidiano do serviço também pode ser explicada para além da formação ineficiente, pois os profissionais fazem parte do sistema social e, dentro deste, estão expostos às questões representacionais históricas em relação ao negro, imbuídos do pensamento de democracia racial, que encobre os determinantes e condicionantes da saúde da população negra e sua relação com o ambiente social, afetando diretamente as condições e qualidade de vida destas pessoas.

Evidenciou-se, no estudo, a inexistência de ações realizadas pelos enfermeiros no tocante à saúde da população negra e racismo institucional e a falta de conhecimento destes em relação ao tema. Entretanto, os mesmos percebem a orientação, capacitação, educação permanente e continuada para os profissionais, assim como o trabalho de educação sobre o tema com a população, baseando-se no respeito às características étnicas e raciais, como principal meio de prevenção do racismo institucional e desconstrução deste, fator que é positivo para o enfrentamento do problema.

Em contrapartida, este estudo teve como limitação a inexistência de investigação da percepção do negro sobre o racismo institucional na saúde pública, fator este que possibilitaria melhor compreensão deste determinante para o acesso à saúde na realidade estudada. Além disso, foi possível perceber que este constitui tema pouco debatido no setor público de saúde, apresentando reduzido número de evidências científicas. Deste modo, há a necessidade da 
Percepções e ações dos enfermeiros em relação ao racismo institucional na saúde pública... | 16

realização de novos estudos com novas abordagens e métodos, visando a integração do tema no meio científico e estigando o interesse público e dos profissionais pelo mesmo. Assim, considera-se importante a realização de um novo estudo, investigando a percepção dos negros em relação ao racismo institucional na saúde pública, para que seja possível a reflexão sobre os dados levantados e sua publicação de maneira a estimular a formação de programas e políticas direcionadas para as necessidades de saúde desta população.

Visto isso, a enfermagem, enquanto profissão do cuidado, integrante da equipe de saúde, responsável pela gestão e oferta do atendimento de qualidade, deve pautar-se em fundamentos e recursos que viabilizem o trabalho sobre as necessidades da população assistida. Além disso, deve possuir uma visão holística e integradora que permita reconhecer as especificidades de cada usuário do serviço, respeitando os seus direitos como pessoa e cidadão, independente de raça, cor ou etnia.

\section{Referências}

1. Brasil. Ministério da Saúde. Secretaria de Políticas de Promoção da Igualdade Racial. Racismo como determinante social de saúde. Brasília (DF): Ministério da Saúde; 2011. [acesso em 2018 jul 09]. Disponível em: $\quad$ https://www.mdh.gov.br/biblioteca/igualdade-racial/racismo-como-determinante-social-desaude/view.

2. Brasil. Ministério da Saúde. Secretaria de Gestão Estratégica e Participativa. Departamento de Apoio à Gestão Participativa. Políticas de Promoção da Equidade em Saúde. Brasília (DF): Ministério da Saúde; 2013. [acesso em 2018 jul 09]. Disponível em: http://bvsms.saude.gov.br/bvs/publicacoes/politica_prococao_equidade_saude.pdf.

3. Brasil. Ministério da Saúde. Secretaria de Gestão Estratégica e Participativa. Departamento de Apoio à Gestão Participativa. Política Nacional de Saúde Integral da População Negra: uma política do SUS. $3^{a}$ ed. Brasília (DF): Ministério da Saúde; 2017. [acesso em 2018 nov 17]. Disponível em: http://bvsms.saude.gov.br/bvs/publicacoes/politica_nacional_saude_populacao_negra_3d.pdf.

4. Santos JE, Santos GCS. Narrativas dos profissionais sobre a política nacional de saúde integral da população negra. Saúde Debate [Internet]. 2013 out [acesso em 2016 nov 09]; 37(99):563-70. Disponível em: http://www.scielo.br/pdf/sdeb/v37n99/a03v37n99.pdf. doi: http://dx.doi.org/10.1590/S010311042013000400003. 
5. Inocêncio JF, Souza MMT. A percepção do enfermeiro quanto à saúde do negro. Rev Pró-UniverSUS [Internet]. 2014 jul [acesso em 2016 out 26];5(2):11-7. Disponível em: editora.universidadedevassouras.edu.br/index.php/RPU/article/view/515/344.

6. Bardin L. Análise de conteúdo. São Paulo (SP): Edições 70; 2011.

7. Faria MA, Silva AJ. A educação das relações étnico-raciais na formação em gestão de serviços de saúde. Rev Bras Ensino Super [Internet]. 2016 jan [acesso em 2016 ago 18];1(2):34-40. Disponível em: https://seer.imed.edu.br/index.php/REBES/article/view/1103. doi: http://dx.doi.org/10.18256/24473944/rebes.v2n1p34-40.

8. Monteiro RB. Educação permanente em saúde e as Diretrizes Curriculares Nacionais para Educação das relações étnico-raciais e para ensino de História e Cultura Afro-Brasileira e Africana. Saúde Soc [Internet]. 2016 jul [acesso em 2018 ago 03];25(3):524-34. Disponível em: http://www.scielo.br/pdf/sausoc/v25n3/1984-0470-sausoc-25-03-00524.pdf.

9. Chehuen Neto JA, Fonseca GM, Brum IV, Santos JLCT, Rodrigues TCGF, Paulino KR, et al. Política Nacional de Saúde Integral da População Negra: implementação, conhecimento e aspectos socioeconômicos sob a perspectiva desse segmento populacional. Ciênc Saúde Colet [Internet]. 2015 jun [acesso em 2016 out 07];20(6):1909-16. Disponível em: http://www.scielo.br/pdf/csc/v20n6/1413-8123-csc20-06-1909.pdf. doi: http://dx.doi.org/10.1590/1413-81232015206.17212014.

10. Teixeira CF, Araújo MVR. Formulação da política de saúde da população negra em salvador: atores e propostas. Rev Baiana Saúde Pública [Internet]. 2013 out [acesso em 2016 ago 18];37(4):891-913. Disponível em: http://files.bvs.br/upload/S/0100-0233/2013/v37n4/a4485.pdf.

11. Tavares NO, Oliveira LV, Lages SRC. A percepção dos psicólogos sobre o racismo institucional na saúde pública. Saúde Debate [Internet]. 2013 out [acesso em 2016 out 24]; 37(99):580-7. Disponível em: http://www.scielo.br/pdf/sdeb/v37n99/a05v37n99.pdf. doi: http://dx.doi.org/10.1590/S010311042013000400005.

12. Gomes HMS. "Pia, é negro e só quer ser o que não é": interface entre racismo, saúde, doenças e práticas culturais. Cad Imbondeiro [Internet]. 2014 [acesso em 2018 nov 17];3(2). Disponível em: http://periodicos.ufpb.br/index.php/ci/article/view/21673/12879.

13. Rodrigues DS, Barros MMA. Racismo institucional e desigualdades sociais no Brasil: um olhar para a universalidade no Sistema Único de Saúde. Rev Inter [Internet]. 2014 [acesso em 2016 nov 14];1:1-14. Disponível em: http://docplayer.com.br/6856856-Racismo-institucional-e-desigualdades-sociais-no-brasil-um-olhar-para-auniversalidade-no-sistema-unico-de-saude-1.html.

14. Geledés - Instituto da Mulher Negra. Secretaria de Políticas de Promoção da Igualdade Racial. Guia de enfrentamento do racismo institucional. São Paulo (SP): Ibraphel Gráfica; 2013. [acesso em 2016 jul 09]. Disponível em: http://www.onumulheres.org.br/wp-content/uploads/2013/12/Guia-de-enfrentamentoao-racismo-institucional.pdf. 
15. Faria MA, Silva AJSA. Educação das relações étnico-raciais na formação em gestão de serviços de saúde. Rev Bras Ensino Super [Internet]. 2016 jan [acesso em 2018 nov 17];1(2): 34-40. Disponível em: https://seer.imed.edu.br/index.php/REBES/article/view/1103.

16. Mendes VS, Costa CS, Ribeiro LR. Racismo biológico e suas implicações no ensinar-cuidar da população negra. Rev ABPN [Internet]. 2015 [acesso em 2016 ago 18];7(16):190-213. Disponível em: http://www.abpnrevista.org.br/revista/index.php/revistaabpn1/article/view/104/101.

17. Fraga FA, Sanino GEC. Saúde da mulher negra passos e descompassos: ações afirmativas na saúde, provável luz no fim do túnel? Rev ABPN [Internet]. 2015 fev [acesso em 2016 jan 2];7(15):192-211. Disponível em: http://www.abpnrevista.org.br/revista/index.php/revistaabpn1/article/view/121/118.

18. Prestes CRS, Paiva VSF. Abordagem psicossocial e saúde de mulheres negras: vulnerabilidades, direitos e resiliência. Saúde Soc [Internet]. 2016 [acesso em 2018 nov 17]; 25(3);673-88. Disponível em: http://www.scielo.br/pdf/sausoc/v25n3/1984-0470-sausoc-25-03-00673.pdf.

19. Werneck J. Racismo institucional e saúde da população negra. Saúde Soc [Internet]. 2016 [acesso em 2018 nov 17];25(3):535-49. Disponível em: http://www.scielo.br/pdf/sausoc/v25n3/1984-0470-sausoc-25-0300535.pdf.

20. Grandi J, Dias MTG, Glimm S. Percepções daqueles que perguntam: qual a sua cor? Saúde Debate [Internet]. 2013 out [acesso em 2016 nov 16];37(99):588-96. Disponível em: http://www.scielo.br/pdf/sdeb/v37n99/a06v37n99.pdf. doi: http://dx.doi.org/10.1590/S010311042013000400006.

21. Markle WH, Fisher MA, Junior RAS. Compreendendo a saúde global. Porto Alegre: AMGH; 2015.

22. Queiroz SB. Relato de experiência docente para a educação étnico-racial em uma universidade de Ciências da Saúde. Cad Imbondeiro [Internet]. 2014 [acesso em 2016 ago 18]; 3(2):1-11. Disponível em: http://periodicos.ufpb.br/index.php/ci/article/view/21739/12833.

23 Eurico MC. A percepção do assistente social acerca do racismo institucional. Serv Soc Soc [Internet]. 2013 abr [acesso em 2016 nov 09];114:290-310. Disponível em: http://www.scielo.br/pdf/sssoc/n114/n114a05.pdf. doi: http://dx.doi.org/10.1590/S0101-66282013000200005.

24. Alves GJ, Leandro SS. Abordagem a populações em situação de vulnerabilidade na atenção primária à saúde. In: Associação Brasileira de Enfermagem, Kalinowski CE, Crozeta K, Fonseca RMGS, organizadores. PROENF: Programa de atualização em enfermagem: atenção primária e saúde da família. Ciclo2. Porto Alegre: Artmed Panamericana; 2014. p. 93-124.

25. Correio TPF, Correio HBRE. Da abolição às ações afirmativas: a luta pela igualdade racial no Brasil e as contribuições do Serviço Social. Emancipação [Internet]. 2014 ago [acesso em 2016 ago 18];14(2):221-30. Disponível em: http://www.revistas2.ue pg.br/index.php/emancipacao/article/view/5238/4961. doi: http://dx.doi.org/10.5212/Emancipacao.v.14i2.0004. 


\section{Autor correspondente}

Luiz Gustavo Fernandes da Rosa

E-mail: enfermeiro.luizgustavofr@outlook.com

Endereço: Av. Darcy Feijó, 709, Capão da Canoa, Rio Grande do Sul, Brasil.

CEP: 95555-000

\section{Contribuições de Autoria}

\section{1 - Luiz Gustavo Fernandes da Rosa}

Contribuições: concepção, planejamento, coleta, análise e interpretação dos dados, redação e revisão crítica do conteúdo.

\section{2 - Renata Gomes Christóvão}

Auxílio no planejamento, análise e interpretação dos dados.

\section{3 - Mirela Furlin}

Auxílio na interpretação dos dados, redação e revisão crítica.

\section{4 - Jeanice Baecker Lasta}

Revisão crítica do conteúdo e participação na aprovação da versão final do manuscrito.

\section{Como citar este artigo}

Rosa LGF, Christóvão RG, Furlin M, Lasta JB. Percepções e ações dos enfermeiros em relação ao racismo institucional na saúde pública. Rev. Enferm. UFSM. 2019 [Acesso em: 2019 jun 15];vol ex:1-19. DOI:https://doi.org/10.5902/2179769231131 